\title{
Review
}

\section{It's not all about inhaled treatment: challenges with oral therapy in paediatric respiratory medicine}

Advances in therapies and management of conditions encountered by paediatric respiratory specialists have led to improved outcomes and improved survival rates dramatically in chronic diseases such as cystic fibrosis. However, this has also meant an increase in treatment burden. A variety of inhaled treatments are crucial in managing paediatric respiratory diseases, but these patients also have to take many oral medications. It is widely recognised that developing oral formulations appropriate for the paediatric population can affect how well a product is received by patients and their families. Consideration should be given to palatability and the number of medicines to be administered as these can all contribute to treatment adherence.

Polypharmacy specifically in the context of management of patients with cystic fibrosis is not a new concept, but the recently introduced cystic fibrosis transmembrane conductance regulator (CFTR) modulator therapies and their potential for interactions and adverse reactions create novel challenges. There are some strategies that families and healthcare professionals can implement to reduce treatment burden. This review will also provide some insight into the life of a teenager with cystic fibrosis and the relative complexities of her treatment and the impacts on daily life.

\section{Educational aims}

- To describe the difficulties faced by children with long-term respiratory conditions having to take oral medication.

- To discuss oral drug interactions that may exist within paediatric respiratory medicine and to consider issues with polypharmacy.

- To highlight strategies that may be used to reduce the burden of care for children on oral medication.

@ERSpublications

In children, medications given by the oral route can be challenging to administer, add to the burden of care and contribute to poor adherence. Additionally, polypharmacy increases the chances of interactions between oral medications. https://bit.ly/3fxgXQU
Cite as: Sareen A, Ramphul M, Bhatt JM. It's not all about inhaled treatment: challenges with oral therapy in paediatric respiratory medicine. Breathe 2021; 17: 210005

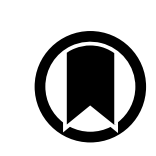

CrossMark

(C) ERS 2021 


\section{Case vignette}

A typical day in the life of a 16-year-old with cystic fibrosis (CF) and persistent nontuberculous mycobacterial (NTM) infection is described by her parent in box 1 .

Her daily routine includes several inhalers, nebulisers and airway clearance twice daily. This is not the end of it: the routine gets even more challenging as she has to endure taking multiple oral medications (tablets, capsules and oral suspensions) (figure 1). These are all to be taken at different times of the day, and many of them do not taste very nice at all. Adherence with oral treatment is difficult; she feels nauseated with some of her treatment, which is then managed though the introduction of new oral medicines in the form of anti-emetics. Additionally, she has to

\section{Box 1 The parent's view}

As the carer of a teenager with CF, I live with the constant feeling that I have forgotten something. When I started to write a list of all her treatments, I had this feeling (that I had forgotten something) so strongly that I decided to go through her daily routine for an average school day instead to give an idea of what goes on.

\section{On waking}

- Disconnect feed.

- Give percutaneous endoscopic gastrostomy (PEG) meds (co-trimoxazole, ursodeoxycholic acid, multivitamins).

- Check blood sugar and give oral meds (Kaftrio, azithromycin, minocycline, clofazimine).

- Set up nebulised amikacin.

- Nag about NovoRapid and creon if breakfast is on the cards and remember to check she has her BM machine in her schoolbag (not that she remembers to use it at school!).

- Dad stands over her whilst she does physio and the nebuliser as compliance is not great if left to her own devices. This has become one of dad's jobs as I got fed up with the eye-rolling and attitude that daughters seem to give their mums and not their dads!

\section{At school (in theory)}

- Blood sugar before lunch and before leaving school.

- Creon and NovoRapid with lunch (I suspect not often).

This morning I had a few CF admin jobs after the school run: call to Nutricia as no extension sets came with yesterday's feed delivery, call to Pari as we need a new plug and nebuliser head for the eFlow, returned a call from DWP as our daughter was 16 the other day and DLA turns into PIP at age 16.

\section{On return from school}

- Blood sugar and food as usually starving!

- More nagging about creon and NovoRapid.

- Dornase via iNeb (again usually with supervision as can be a bit crafty with it, at least you can see whether she's done it from the number on the disc).

\section{About 9pm}

- Physio and then nebulised amikacin via the eFlow (again dad in attendance!)

\section{Bedtime (usually overseen by me)}

- Set up feed.

- Give meds (Lantus, Kalydeco, creon, co-trimoxazole and iron supplement via the PEG.) Three nights a week she has an injection of interferon- $\gamma$.

Once a week we change the water in the balloon (more eye-rolling!). Every 3-4 months we change the button. One of our trusty nurses comes once a month to flush the port.

Other admin tasks include ordering meds from three different sources: general practitioner (GP), hospital and the homecare company. We also need to source needles and syringes for the interferon and for the amikacin (unusually from Amazon!).

Then there's the psychological stuff.

My daughter usually seems pretty accepting, but she does get cheesed off especially with me. Mainly I suspect she gets fed up with me being in and out of her room, which is her teenage sanctuary. I have to make sure I knock these days!

From my point of view, I frequently feel guilty l've forgotten a treatment or inadequate if we've run out of something and I haven't ordered it in time. Packing to go on holiday stresses me out entirely: I'm terrified offorgetting a nebuliser or the insulin, etc. (I write lots of lists!).

All in all, it's a full-time job but she's worth it! 


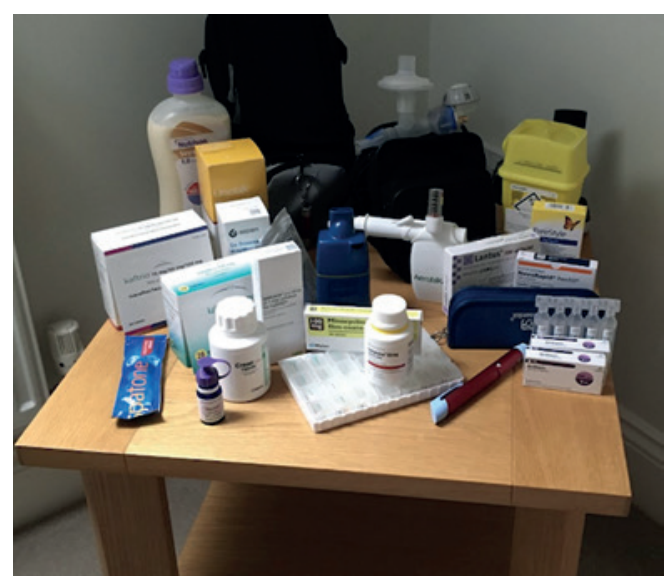

Figure 1 Treatments taken each day (including oral, subcutaneous and nebulised medication and medicines/feeds via the gastrostomy).

have overnight feeds via the gastrostomy and have regular admissions to the hospital for intravenous antibiotics.

After discussion with her doctors and pharmacist, changes to her medication are made to help with the treatment burden. For example, rather than taking ursodeoxycholic acid in tablet form at $450 \mathrm{mg}$ twice daily, she started taking $1 \mathrm{~g}$ once daily as a liquid. In view of the nausea with moxifloxacin being used to treat NTM, she is changed to minocycline.

She has a gastrostomy to optimise her nutrition and the gastrostomy also alleviates some of the discomfort with swallowing tablets; this involves changing a few of the medicines to liquid formulations.

Her list of oral medications remains extensive:

- Creon 25000 capsules, up to 5 per day

- Omeprazole MUPS 20 mg, once daily

- Multivitamin liquid $0.5 \mathrm{~mL}$, alternate days

- Ursodeoxycholic acid liquid $1 \mathrm{~g}$, once daily

- Iron supplements 1 sachet, once daily

- Azithromycin liquid 250 mg, once daily

- Minocycline tablets $75 \mathrm{mg}$, once daily

- Clofazimine tablets 50 mg, once daily

- Metoclopramide liquid, as needed

- Ondansetron liquid, as needed

- Paracetamol liquid, as needed

- Ivacaftor $75 \mathrm{mg}$, Tezacaftor $50 \mathrm{mg}$ and Elexacaftor $100 \mathrm{mg}$ (Kaftrio) 2 tablets in the morning with 1 tablet of Ivacaftor $150 \mathrm{mg}$ (Kalydeko®) in the evening

Inhaled/nebulised and injectable treatments:

- Dornase alfa $2.5 \mathrm{mg}$, once daily

- Interferon- $\gamma$ 1B $60 \mu$ g, three times weekly

- Salbutamol $100 \mu$ g per dose metered-dose inhaler 2 puffs, twice daily

- Insulin administered as directed with meals

\section{Introduction}

Swallowing tablets can be a challenge for young children who are yet to develop oro-motor oral skills, as well as for teenagers who dislike the sensation of swallowing medication. This may be a particular problem in paediatric respiratory medicine, for example in CF, where children may be on multiple oral medications. Alternative preparations, such as liquid formulations may be employed, but other issues such as palatability and side-effects (e.g. nausea) may also be contributing factors leading to poor adherence. The burden of care with oral medication is substantial for children and their families.

\section{What is adherence?}

The World Health Organization defines adherence as "the extent to which a person's behaviour - taking medication, following a diet, and/or executing lifestyle changes, corresponds with agreed recommendations from a health care provider." [1]. There are three stages where adherence to oral medication can falter in children with respiratory disease [2].

1) Failure to initiate prescribed treatment. Initiation of treatment refers to the first time the child takes the treatment and this is a binary event, with patients either starting to take their oral medication or not.

2) Failure to implement treatment as prescribed. Children may skip their medication at certain times or on certain days, due to personal factors or side-effects of the medication such as nausea.

3) Non-persistence with treatment. Persistence relates to the extent to which patients take medication for the duration intended by the medical team, as paediatric patients may opt to stop taking the medication earlier than directed.

One study involving 100 paediatric patients aimed to identify levels of adherence to specific treatments used in the management of CF. Low adherers were defined as those who had $<80 \%$ of their medicines dispensed against the quantity prescribed during the studied period. It identified that " $72 \%$ of patients were classed as low adherers to enzyme supplements; $59 \%$ were low-adherers to vitamins and $49 \%$ were low adherers to chest physiotherapy" [3]. While this study focused on some (and not all) treatments used in the management of CF, it can help to provide a general indicator of adherence levels within the paediatric CF population.

Adherence to oral medication in paediatric respiratory medicine is influenced by a variety of factors which will be explored below.

\section{Types of formulations}

CF is a multi-system disease, whose treatment requires polypharmacy. It is widely recognised 
that the survival rates for people with CF have dramatically improved [4], due to improvement in management and development of new treatments [5, 6]. Management includes not only inhaled or nebulised medication, but also a wide array of oral medication such as: prophylactic and/ or maintenance oral antibiotic therapies; pancreatic enzyme replacement therapy; fat-soluble vitamins; and other nutritional therapies.

In addition to the burden of oral and inhaled maintenance treatment, intravenous antibiotics may also be needed depending on the clinical status.

The oral therapies that are used are available in a variety of formulations and all licensed preparations can be found in the British National Formulary for Children (BNFc) and/or summary of product characteristics (SPCs) on the electronic medicines compendium (EMC) $[7,8]$. It is worth noting that although licensed preparations exist, a number of medicines will not be licensed for use in certain respiratory conditions (e.g. azithromycin is often used for prophylactic and treatment purposes in CF and azoles, such as itraconazole, voriconazole and posaconazole, are used in the treatment of allergic bronchopulmonary aspergillosis (ABPA) but are not recognised in their license for these indications) [7, 9]

\section{Non-interchangeable oral formulations}

While a medicine may be available in a variety of formulations, there are some instances where formulations are not interchangeable.

Posaconazole is also used for the treatment of ABPA and there is some research to indicate that it is superior compared with other azoles in terms of treatment success [10]. Posaconazole tablets and posaconazole liquid are not interchangeable and so the same formulation should be used throughout a treatment course [11, 12]. A retrospective study assessing clinical effectiveness of posaconazole tablets versus posaconazole liquid in lung transplant patients with Aspergillus identified that posaconazole tablets could be better relied upon for consistent posaconazole levels [13].

By contrast, serum concentrations of itraconazole are higher when the oral solution is used instead of the capsules (despite the same dose of drug being administered) [14, 15].

Ivacaftor (Kalydeko), lumacaftor/ivacaftor (Orkambi), tezacaftor/ivacaftor (Symkevi) and elexacaftor/tezacaftor/ivacaftor (Kaftrio) are all cystic fibrosis transmembrane conductance regulator (CFTR) modulator therapies that will potentiate or correct the CFTR pathway caused by defective variants within the CFTR gene [16, 17]. Ivacaftor (Kalydeko) and lumacaftor/ivacaftor (Orkambi) are available as granules and tablets and the remaining CFTR modulators are all available as tablets only [7]. Ivacaftor (Kalydeko) and lumacaftor/ivacaftor
(Orkambi) are licensed for use in younger patients ( 4 months and 2 years of age, respectively), and are available in a variety of formulations including granules. The license for tezacaftor/ivacaftor (Symkevi) is for patients aged over 6 years and elexacaftor/tezacaftor/ivacaftor (Kaftrio) at the time of writing is for patients aged 12 years and over, and both are only currently available as tablet formulations.

Given previously identified variable levels of adherence to certain treatments used within CF [3], it remains to be seen whether these rates will be transferrable and applicable to CFTR modulators (and how these will balance against the relative cost of these drugs) [7].

\section{Issues around palatability, swallowing of medication or lack of suitable formulations}

Guidance published by the European Medicines Agency (EMA) recognises that it is of great importance to develop medication for use within paediatrics that is age-appropriate and to a consistently high standard without impacting unnecessarily on patients and their families in terms of treatment burden [18]. It also identified that patient acceptance of a particular product will affect whether patients are adherent and hence determine how effective and safe a treatment is. Issues such as palatability, appearance, the volume/number of doses (for liquids and tablets, respectively) and dosing frequency can have a significant impact on how well a product is received.

The Smart Paediatric Drug Development UK Project (SpaeDD-UK project) [19] worked to develop a theoretical algorithm to determine and describe what will be considered an acceptable medicine form for different age groups based on their own review of the limited information available. The project itself recognised the lack of primary research to indicate the size and number of tablets appropriate for each age group, which may support the somewhat surprising suggestions in table 1. It is thought that the suggestions may help in guiding decisions about the design and development of paediatric formulations that will probably be considered acceptable by different age groups.

\section{Factors influencing starting to take tablets}

There are a number of factors that will influence when a paediatric patient will be able to safely swallow tablets, but it is generally considered appropriate for individuals aged 6 years and upwards. For paediatric patients with chronic respiratory disease, it is thought that those aged as 
Table 1 Algorithm on acceptable medicine forms for different age groups

\begin{tabular}{|c|c|c|c|c|c|}
\hline & Liquid\# & Conventional or minitablet & $\begin{array}{l}\text { Multi- } \\
\text { particulate }\end{array}$ & $\begin{array}{c}\text { Orodispersible } \\
\text { tablet }\end{array}$ & $\begin{array}{c}\text { Chewable } \\
\text { tablet }\end{array}$ \\
\hline Neonates & $\begin{array}{l}<0.5 \mathrm{~mL} \text { volume } \\
\text { Neutral taste }\end{array}$ & $2 \mathrm{~mm}$ minitablet acceptable & $x$ & $x$ & $x$ \\
\hline Infants & $\begin{array}{l}<2.5 \mathrm{~mL} \text { volume } \\
\text { Neutral taste }\end{array}$ & $\begin{array}{l}<3 \mathrm{~mm} \text { tablet } \\
\text { Up to } 3 \text { tablets per dose }\end{array}$ & Neutral taste & $\begin{array}{l}<6.5 \mathrm{~mm} \text { tablet } \\
\text { Neutral taste }\end{array}$ & $x$ \\
\hline $\begin{array}{l}\text { Children aged } \\
6-12 \text { years }\end{array}$ & $\begin{array}{l}<10 \mathrm{~mL} \text { volume } \\
\text { Neutral taste }\end{array}$ & $\begin{array}{l}\quad<7 \mathrm{~mm} \text { tablet } \\
\text { Up to } 3 \text { tablets per dose }\end{array}$ & Neutral taste & $\begin{array}{l}<9.5 \mathrm{~mm} \text { tablet } \\
\text { Neutral taste }\end{array}$ & $\begin{array}{c}<14.7 \mathrm{~mm} \text { tablet } \\
\quad \text { Neutral taste }\end{array}$ \\
\hline
\end{tabular}

young as 3 years old may be able to swallow tablets following appropriate training and support from the multidisciplinary team and family (particularly where the alternative is a liquid formulation not tolerated due to taste) [18]. To further add to this, a feasibility study identified that tablets could be a possibility for patients aged 4 years and upwards, and that for younger patients, larger tablets may be easier to swallow (although an average of $8 \mathrm{~mm}$ diameter were tolerated across the studied age group of 4-12 years old) [20].

A variety of methods can be adopted to support children in successfully swallowing tablets including behavioural techniques and changing head positions (as this can impact on swallowing) [21-23].

"Pill schools" entail well-designed services, where children are seen by psychologists and play therapists for an initial assessment, followed by subsequent visits to set the scene, allow children to practice, allow parents to explore and tackle their individual child's worries and preferences, and reward the child with praise for their attempts. Families are also taught the techniques of positive reinforcement to help their children. This has been shown to be effective in children as young as 6 years old [24-26].

Pill schools have won the favour of both children and families who report that taking tablets is less stressful than taking liquids, and also of professionals who recognise that tablets are cheaper, have fewer excipients, may have modified-release mechanisms, and have a better safety profile in terms of ensuring the correct dose is administered.

Medicines for Children have also developed an informative leaflet that can be downloaded or printed that provides practical information to help children swallow tablets or capsules [27].

\section{Alternatives to tablets: liquid formulations}

Considering the appropriateness of excipients particularly in liquid formulations for paediatric patients can also provide challenges [18]. Excipients within a medicine will exist to serve a specific purpose, for example acting as a diluent or preservative [28]. It is well recognised that liquid formulations will need to be preserved (to support an appropriate shelf life of the product) whereas tablets will generally not require this [18].

Excipients such as benzyl alcohol, ethanol, sorbitol and propylene glycol may be of detriment to paediatric patients if present in sufficient quantities [29].

A variety of natural and artificial sweeteners are used in drug formulations to augment the sweetness and thereby palatability of the product. One or more sweeteners (for example aspartame, a phenylalanine-containing synthetic sweetener) can be found in up to $50 \%$ of medications including commonly prescribed antibiotics [30]. Omission and inaccuracy of drug labelling information on pharmaceutical excipients may expose susceptible individuals to adverse reactions caused by these agents [31]. Complications of inadvertent intake of sugar-containing medicines are not only a growing concern among dentists [32], but can also cause problems for children with diabetes, or patients with phenylketonuria due to the intake of aspartame [31]. The choice of an oral antibiotic is very restricted for a preschool-age child with phenylketonuria, who cannot swallow tablets and requires oral antibiotics for community-acquired pneumonia.

While the risk of under- or over-dosing with liquid formulations is a possibility, the EMA specifies that the relative "ease and accuracy of administration" should form part of the pharmaceutical development of a product. Measuring devices such as syringes or cups should always be provided (unless specifically justified not to) [18]. With oral suspensions, there may be some separation of active ingredient from the vehicle in which it has been suspended. Consideration to appropriate patient counselling is required, as the risk of under- or over-dosing in this case can be resolved by shaking the oral suspension prior to use [18]. 
In November 2019, Merck announced that manufacture of theophylline capsules (Slo-Phyllin) would be discontinued with immediate effect once supplies in circulation had been used [33]. Theophylline is indicated in the treatment of asthma for patients aged 2 years and over [7, 34-36], but the only licensed formulation now available are the prolonged release tablets (Uniphyllin Continus) [33] There is also an unlicensed special liquid formulation available. Theophylline capsules (Slo-Phyllin) were usually administered twice daily and for patients unable to swallow the capsules whole, there was the option of opening and emptying the contents of capsules onto a spoonful of soft food [34-36]. While the prolonged release tablets (Uniphyllin Continus) are also dosed at twice daily, the tablets themselves cannot be split, crushed or chewed as this may result in unreliable release of theophylline and potential toxicity (especially as theophylline is a drug with a narrow therapeutic window) [33-36]. Whilst the unlicensed liquid can be used in patients unable to swallow the prolonged release tablets whole, dosing frequency would increase to four times daily. The change to the liquid formulation would obviously increase the treatment burden, but with a lack of other suitable formulations available, would be a necessary addition.

Azithromycin is a macrolide antibiotic that is commonly used as prophylactic treatment against lower respiratory tract infections in children who are at increased risk. There is a variation in azithromycin regimes prescribed, but one survey of paediatric departments in Eastern England found that the most common regime prescribed is three times weekly: Monday, Wednesday and Friday [37].

The branded azithromycin powder for suspension, Zithromax, has a shelf life of 5 days once reconstituted potentially resulting in frequent trips to the community pharmacy for families to collect this product or the reliance on families to correctly reconstitute the product at home [38]. The generic azithromycin suspension offers a slightly longer shelf of 10 days once reconstituted [39]. While tablets and capsules are an option, the lowest strength available is $250 \mathrm{mg}$, which may not always be feasible to prescribe [7].

Increasing amounts of evidence have linked paediatric respiratory disease to gastro-oesophageal reflux disease, but the exact underlying mechanisms are not known [40]. It therefore comes as no surprise that anti-reflux medications are commonly prescribed in children with respiratory disease. A supply disruption alert issued by the Medicines and Healthcare products Regulatory Agency (MHRA) and updated in December 2019 stated that ranitidine tablets, effervescent tablets and oral solution would be unavailable for prescribing until further notice [41]. This has meant reliance on other $\mathrm{H}_{2}$ receptor antagonists or proton pump inhibitors (PPIs) if children still need anti-reflux medication [41]. This has undoubtedly presented some challenges for Trusts and clinical teams to carefully consider other agents for use. To take omeprazole as an example of a commonly used PPI, capsules, tablets and dispersible tablets and a relatively recently available licensed liquid are all available for prescribing [7]. Consideration would need to be given if enteral feeding tubes are to be used for medication administration, as the omeprazole dispersible tablets, in particular, can block fine-bore feeding tubes [41]. While the recently licensed liquid may seem an obvious choice for use, the relative cost of this product against the other formulations would also need to be considered [7], especially if continued use of antireflux medication is required. Both the European Society for Paediatric Gastroenterology Hepatology and Nutrition (ESPHAGAN) and National Institute for Health and Care Excellence (NICE) guidelines recommend PPIs should be started and trialled for an 8-week period, then a trial off medication is recommended [42, 43].

Prednisolone, amongst other indications, is used for the treatment of acute asthma episodes in children [44]. Doses given are dependent on age and treatment courses of 3 days are considered appropriate, but longer courses may be required. It is well recognised that administration of crushed prednisolone tablets is difficult in children due to their bitter taste in those who are unable to swallow tablets whole [45]. Whilst it is reported that prednisolone oral solution is generally better tolerated in children compared with crushed tablets [46], the relative cost of the solution compared with the tablets does mean that in practice, the practice of using crushed tablets is generally preferred [7, 47]. The tablets themselves, when crushed, can be mixed with a small amount of soft food such as yoghurt or jam to disguise the bitter taste [47].

Generally, most medicines used within the treatment of CF are available as licensed preparations: tablets, capsules or liquid formulations. On some occasions, due to palatability or volume of solution required, for example, licensed available formulations may not be appropriate. Where there are not licensed preparations available, some centres do manufacture unlicensed preparations for use locally and nationally. Resources such as The NEWT guidelines for administration of medication to patients with enteral feeding tubes or swallowing difficulties or unpublished advice obtained from manufacturers can guide as to whether tablets can be crushed, the contents of capsules opened and emptied or whether i.v. preparations can be used orally [48]. In these situations, however, there should always be an appreciation that the pharmaceutical properties of the product may be altered and will not have been included as part of the original trial data prior to receiving a product license [18].

Difficulties with administration of certain CF treatments have been acknowledged and recognised.

As part of the "Prevent and treat" arm of the CF START trial [49], patients may be randomised 
to receive flucloxacillin twice daily. It was widely reported whilst preparing for the trial that the taste of flucloxacillin liquid had been a barrier to continuing with treatment. Research was conducted by the University of Birmingham where some solutions were identified to the issue around palatability [50, 51]:

- Persistence with administration;

- Switching the brand of flucloxacillin provided by the pharmacy;

- Switching to the more concentrated solution of $250 \mathrm{mg} / 5 \mathrm{~mL}$ instead of $125 \mathrm{mg} / 5 \mathrm{~mL}$;

- Using the oral syringe generally provided with the solution to dispense instead of a spoon;

- Lots of positive reinforcement provided to the child; and

- Considering use of capsules if the child is old enough to swallow these whole.

Creon is available as both gastro-resistant capsules and gastro-resistant granules [7]. The manufacturers [52] advise that, if necessary, the capsules can be opened and taken with fruit juices or soft food but must not be chewed. One study found that in a patient cohort aged 6-36 months, parents found it easier to use the measure provided with the gastro-resistant granules rather than opening the capsules and using the contents, particularly where small doses were required [53].

These are only a few examples that highlight the importance of tailoring medicine formulations to the patient and particularly in patients with chronic disease.

\section{Polypharmacy}

Polypharmacy can be broadly defined as the use of a number of medicines in any given individual [54]. While there is great debate about the numerical value of polypharmacy, a systematic review [55] found that the most commonly reported numerical definition of polypharmacy was if an individual took five or more medicines each day.

Managing patients with CF, a multi-organ disease, inevitably entails that polypharmacy is always a factor to consider in this condition [56]. Whilst polypharmacy within the management of CF is not a new concept, the much-welcomed availability of CFTR modulators for CF patients has introduced a new consideration for multidisciplinary teams in terms of further different formulations, possible adverse reactions and drugdrug interactions with other concurrent therapies. Additionally, metabolic food-drug interactions can occur when the consumption of a particular food modulates the activity of a drug-metabolising enzyme system, resulting in an alteration to the pharmacokinetics of drugs metabolised by that system. Foods that contain complex mixtures of phytochemicals, such as fruits, vegetables, herbs, spices and teas, have the greatest potential to induce or inhibit the activity of drug-metabolising enzymes, although dietary macroconstituents (i.e. total protein, fat and carbohydrate ratios, and total energy intake) can also have effects. Particularly large interactions may result from the consumption of herbal dietary supplements. Cytochrome P450 (CYP) 3A4 appears to be especially sensitive to dietary effects [57].

The CFTR modulator therapies all influence cytochrome P450 pathways [58]. Names of cytochrome $\mathrm{P} 450$ pathways are derived from gene sequences and are allocated according to family and sub-family names and the specific enzyme in question. Drug interactions occur when medicines "share a common P450 pathway," and while this will be a common pathway for a large proportion of interactions, other mechanisms and pathways do exist [58-60].

Enzyme induction generally results in reduced levels of the drug substrate (due to an increase in metabolism of the substrate), unless the substrate is a prodrug that usually undergoes metabolism to its active metabolite. In this situation, there may be potential toxicity. Enzyme inhibition generally results in increased levels of the drug substrate $[60,61]$.

Careful consideration to potential interactions between the CFTR modulators and concomitant therapies is required (Supplementary table S1). The individual product SPCs can be referred to for more information [62-70].

Lumacaftor/ivacaftor (Orkambi), tezacaftor/ ivacaftor (Symkevi) and elexacaftor/tezacaftor/ ivacaftor (Kaftrio) are all considered "black triangle drugs" by the MHRA as they have only become available widely in the UK in the past year [62-71]. Due to their recent availability, there is relatively limited safety data available and so it is encouraged that any suspected adverse reactions are reported using the Yellow Card Scheme so that this data can be utilised in future to guide treatment decisions [72]. The MHRA are keen to monitor all suspected adverse reactions to medicines, but are particularly interested in those that occur in new drugs to the market (e.g. the CFTR modulators) and in children [73]. Whilst reporting this data nationally is key for providing continued medicines safety, it is also important to encourage individuals to report any adverse effects to their GP or clinical teams, as these will sadly contribute towards treatment burden.

\section{Cardiac side-effects of respiratory drugs}

QT prolongation in patients can be drug-induced and is clearly more likely to happen in patients with polypharmacy. Information summarised by the UK Medicines Information service stated that 
this could be primarily due to one of three reasons [74-77].

1) Pharmacodynamic reactions: if more than one drug that can cause QT prolongation is used in a patient, the risk is additive.

2) Pharmacokinetic reactions: whilst a drug itself may not cause QT prolongation, it may change the metabolism of a different agent that can cause QT prolongation. An example of this is where azoles, such as voriconazole, as a CYP3A inhibitor, will inhibit the metabolism of tacrolimus. Both of these agents have the potential to prolong the QT interval in their own right but the combination of both would require a dose reduction of tacrolimus and careful monitoring [78].

3) Electrolyte derangement: drugs affecting electrolyte balance (primarily by causing low potassium or magnesium) can cause QT prolongation. Examples include diuretics, which are known to cause electrolyte disturbances.

Drugs specifically used within paediatric respiratory medicine that may cause QT prolongation include azithromycin, ciprofloxacin, clarithromycin, azole therapy and anti-emetics such as domperidone and ondansetron. This list is by no means exhaustive [77].

While drug interactions will be a key consideration with polypharmacy, it is also worth noting that often to counteract adverse effects of one medicine, another medicine may be prescribed.

\section{Diet and oral medication}

Dietary regimens (e.g. a ketogenic diet for treatment of epilepsy), or diet as a treatment (e.g. special formula in phenylketonuria) or dietary choices (e.g. grapefruit juice), can occasionally further contribute to the complex interactions (not only via the cytochrome $\mathrm{P} 450$ pathway) between things consumed orally. Whilst a rare occurrence, for children with complex respiratory problems, who are on a ketogenic diet for treatment of epilepsy, avoidance of carbohydrates in medication is incredibly important [79]. While it may not be possible to completely eliminate carbohydrate contributions from medication, avoiding liquid formulations and opting for tablets is usually considered more appropriate [79].

While a variety of resources are available to support parents with medication administration in children, one particular study focused on "tried and tested" techniques discussed in 10 internet forums and three main strategies were found: one included involving the child in the process of medication administration whilst openly changing the palatability using food or drink; another involved hiding medication in food and administering it unknown to the child; and the third involved forced administration. The study did not provide any information about the participants (like the number of children or their age ranges) and there is no specific focus on any particular medicines. Despite these limitations, the concluding statements of this study were to highlight some of the unique techniques used by parents with the aim of successfully administering medication to their children and that awareness by healthcare professionals of techniques used can help with future shared decision making with families about treatment choices [80].

Although food can be used to disguise medication, it is important to recognise that not all medications can be taken with food. Montelukast itself is available in a variety of formulations and is indicated in the treatment of asthma in those aged 2 years and older. For individuals aged between 6 months and 5 years old, both granules and chewable tablets are available for prescribing. For those aged between 6 and 14 years old, chewable tablets are available, and tablets alone are available for individuals over 15 years of age $[7,44]$. The chewable tablets should be taken on an empty stomach ( $1 \mathrm{~h}$ before or $2 \mathrm{~h}$ after food). The manufacturers advise that the mean oral bioavailability is $73 \%$ in individuals in the fasted state and is reduced to $63 \%$ when taken with food. To make the chewable tablets more palatable, they are generally available with cherry flavouring [81].

The granules, which are generally used in children under 5 years old, can be given directly or mixed with a spoonful of cold or room temperature soft food such as apple sauce or ice cream [82].

Gastrointestinal side-effects with all formulations of montelukast are common; however, the manufacturers report that studies have shown abdominal pain to be more common in individuals over 2 years of age taking the tablets or chewable tablets, whereas diarrhoea was reportedly more common with the granules in children aged 6 months up to 2 years old. Other notable differences reported are headaches in older patients (age 6 years and over), and hyperkinesia and rash as possible issues in children taking the granules [81, 82].

The MHRA issued a safety alert in 2019 highlighting and reminding all prescribers of the risk of neuropsychiatric reactions with montelukast that could vary from sleep disturbances and agitation (affecting possibly one in 100 individuals) to hallucinations and suicidal ideations (affecting possibly one in 10000 people) [83]. It is reported that, between 2014 and 2018 , there were 219 reports of possible neuropsychiatric reactions against 14 million prescriptions. While the MHRA did not comment on differences in adverse reactions between formulations, it has been reported that nightmares, aggression and behavioural changes were more prevalent in children than in adults [83]. 
What can healthcare professionals do to support patients with taking oral medication?

- Consider the use of commercial medication flavouring products. These are available, but no data supports the long-term stability of medications when mixed with these; they are best added just prior to administration.

- Consider the use of chewable tablets, quick dissolve, or "melting" dosage forms.

- Considering the use of higher strength liquids (if liquid formulations are deemed the most appropriate formulation for the patient).

- Alternative medications that require fewer daily doses or "trial and error" with patients to identify those that are considered more palatable.

- Involvement of clinical psychologists and "pill schools" to support children and their families in administration of tablets.

\section{What can parents do to maximise compliance with oral medication?}

- Mask the taste of medication using food if appropriate.

- Teach children to swallow tablets.

- Try administering medication into different areas of the mouth to assess patient preference (e.g. into cheek, onto back of tongue).

- Explain the benefits/rationale for using the medication, and allow children to choose administration modality (syringe, cup, straw, spoon).

- Positive reinforcement: praise and/or reward for successful medication administration.

\section{Self-evaluation questions}

1. Which of the following CFTR modulators can be administered as granules?
a) Orkambi
b) Symkevi
c) Kaftrio
d) None of the above

2. Which one of the following drugs will most likely cause QT prolongation?
a) Domperidone
b) Orkambi
c) Creon
d) Lansoprazole

3. Which one of the following drugs is a CYP3A inducer?
a) Rifampicin
b) Clarithromycin
c) Posaconazole
d) Erythromycin

4. Which of the following does not help to promote adherence to oral medication in children?
a) Mixing the liquid medication with food to mask the taste
b) Praising children when they take the medication
c) Telling children off when they refuse medication
d) Using a formulation that requires fewer daily doses

\section{Conclusion}

Taking medications orally may be a very important component of the treatment plan for a variety of childhood respiratory conditions. Clinicians must recognise that this places an enormous burden of care on patients and their families. Polypharmacy should be minimised as much as possible, and interactions between oral medications should be considered. There are measures that healthcare professionals and families can put into practice to help with adherence to oral medication.

\section{Key points}

- There is a large burden of care with oral medication for children and their families.

- The challenges with oral medication administration can lead to poor adherence with treatment in long-term respiratory conditions.

- Polypharmacy increases the chances of interactions between oral medications and these should be considered.

- Healthcare professionals and parents can devise strategies that may help with adherence to oral medication. 


\section{Affiliations}

\section{Anneka Sareen', Manisha Ramphul2, Jayesh Mahendra Bhatt ${ }^{2}$}

1Pharmacy Dept, Nottingham Children's Hospital, Nottingham University Hospitals NHS Trust, Queen's Medical Centre, Nottingham, UK. PPaediatric Respiratory Medicine, Nottingham Children's Hospital, Nottingham University Hospitals NHS Trust, Queen's Medical Centre, Nottingham, UK.

\section{Supplementary material}

This article has supplementary material available from breathe.ersjournals.com

\section{Conflict of interest}

None declared.

\section{Suggested answers}

1. a.

2. a.

3. a.

4. c.

\section{References}

1. Sabaté $E$, ed. Adherence to long-term therapies: evidence for action. Geneva, World Health Organization, 2003; p. 198.

2. Vrijens B, Dima AL, Van Ganse E, et al. What we mean when we talk about adherence in respiratory medicine. J Allergy Clin Immunol Pract 2016; 4: 802-812.

3. Goodfellow NA, Hawwa AF, Reid AJM, et al. Adherence to treatment in children and adolescents with cystic fibrosis: a cross-sectional, multi-method study investigating the influence of beliefs about treatment and parental depressive symptoms. BMC Pulm Med 2015; 15: 43.

4. Keogh RH, Szczesniak R, Taylor-Robinson D, et al. Up-todate and projected estimates of survival for people with cystic fibrosis using baseline characteristics: A longitudinal study using UK patient registry data. J Cyst Fibros 2018; 17: 218-227.

5. Castellani C, Duff AJA, Bell SC, et al. ECFS best practice guidelines: the 2018 revision. J Cyst Fibros 2018; 17: 153-178.

6. National Institute for Health and Care Excellence. Cystic fibrosis: diagnosis and management. www.nice.org.uk/ guidance/ng78/resources/cystic-fibrosis-diagnosis-andmanagement-pdf-1837640946373 Date last updated October 25, 2017. Date last accessed: November 22, 2020.

7. Paediatric Formulary Committee. BNF for Children (online). London, BMJ Group, Pharmaceutical Press, RCPCH Publications bnfc.nice.org.uk Date last updated: October 29, 2020. Date last accessed: November 22, 2020.

8. Datapharm Ltd. Electronic medicines compendium (emc.) www.medicines.org.uk/emc\#gref Date last accessed: December 8, 2020.

9. Smyth AR, Barbato A, Beydon N, et al. Respiratory medicines for children: current evidence, unlicensed use and research priorities. Eur Respir J 2010; 35: 247-265.

10. Periselneris J, Nwankwo L, Schelenz S, et al. Posaconazole for the treatment of allergic bronchopulmonary aspergillosis in patients with cystic fibrosis. J Antimicrob Chemother 2019 74: 1701-1703.

11. Merck Sharp \& Dohme Limited. Summary of product characteristics - Noxafil 100 mg Gastro-resistant Tablets. www. medicines.org.uk/emc/product/5388/smpc Date last updated: October 25, 2010. Date last accessed: December 8, 2020.

12. Merck Sharp \& Dohme Limited. Summary of product characteristics - Noxafil $40 \mathrm{mg} \cdot \mathrm{mL}-1$ oral suspension. www.medicines.org.uk/emc/product/176/smpc Date last updated: October 25, 2010. Date last accessed: December 8, 2020.

13. Stelzer D, Weber A, Ihle F, et al. Posaconazole liquid vs tablet formulation in lung transplant recipients. Mycoses 2018; 61: 186-194.

14. Cartledge JD, Midgely J, Gazzard BG. Itraconazole solution: higher serum concentrations and better clinical response rates than the capsule formulation in acquired immunodeficiency syndrome patients with candidosis. J Clin Pathol 1997; 50: 477-480.

15. Beacon Pharmaceuticals. Summary of product characteristics - Itraconazole $10 \mathrm{mg} / \mathrm{mL}$ Oral solution. www.medicines.org. uk/emc/product/3293/smpc Date last updated: February 25, 2020. Date last accessed: December 8, 2020.

16. Elborn JS. Modulator treatment for people with cystic fibrosis: moving in the right direction. Eur Respir Rev 2020; 29 : 200051

17. NHS England. Clinical Commissioning Urgent Policy Statement Cystic Fibrosis Modulator Therapies Access Agreement for licensed mutations [200810P]. www.england.nhs.uk/ wp-content/uploads/2020/08/Policy-statement-CFTRModulator-Therapies-Licensed-mutations.pdf Date last updated: September 4, 2020. Date last accessed: November 22, 2020

18. European Medicines Agency. Guideline on pharmaceutical development of medicines for paediatric use. www.ema. europa.eu/en/documents/scientific-guideline/guidelinepharmaceutical-development-medicines-paediatricuse_en.pdf Date last updated: February 15, 2004. Date last accessed: November 22, 2020.

19. Mistry P, Batchelor H. Evidence of acceptability of oral paediatric medicines: a review. J Pharm Pharmacol 2017 69; 361-376.

20. Bracken L, McDonough E, Ashleigh S, et al. Can children swallow tablets? Outcome data from a feasibility study to assess the acceptability of different-sized placebo tablets in children (creating acceptable tablets (CAT)). BMJ Open 2020; 10: e036508.

21. Kaplan BJ, Steiger RA, Pope J, et al. Successful treatment of pillswallowing difficulties with head posture practice. J Paediatr Child Health 2010; 15:e1-e5.

22. Logemann J, Kahrilas P, Kobara M, et al. The benefit of head rotation on pharyngoesophageal dysphagia. Arch Phys Med Rehabil 1989; 70:767-771.

23. Ohmae Y, Ogura M, Kitahara S, et al. Effects of head rotation on pharyngeal function during normal swallow. Ann Otol Rhinol Laryngol 1998; 107:344-348.

24. Meltzer EO, Welch MJ, Ostrom NK. Pill swallowing ability and training in children 6 to 11 years of age. Clin Pediatrics, 2006; 45: 725-733.

25. Garvie PA, Lensing S, Rai SN, Efficacy of a pill-swallowing training intervention to improve antiretroviral medication adherence in pediatric patients with HIV/AIDS. Pediatrics, 2007;119: 893-899.

26. Northern Paediatrics: Supporting Child Health in the North East and Cumbria. Creating a pill school: Pill swallowing technique. northernpaediatrics.com/kidzmed/pill-school/ Date last accessed: March 12, 2021. 
27. Medicines for Children. Helping your child to swallow tablets. www.medicinesforchildren.org.uk/helping-your-childswallow-tablets Date last updated: November 30, 2017. Date last accessed: November 27, 2020.

28. Rowe RC, Sheskey PJ, Owens SC, eds. Handbook of Pharmaceutical Excipients. 5th Edn. London, Pharmaceutical Press, 2006

29. Nahata MC. Safety of "inert additives or excipients in paediatric medicines. Arch Dis Child Fetal Neonatal Ed 2009; 94: F392-F393.

30. Duggett A. Medications that contain aspartame. www. drugsdb.com/cib/aspartame/medications-that-containaspartame/ Date last updated: June 11, 2012. Date last accessed: December 17, 2020.

31. Balbani AP, Stelzer LB, Montovani JC. Pharmaceutical excipients and the information on drug labels. Braz J Otorhinolaryngol. 200672: 400-406

32. Al Humaid J. Sweetener content and cariogenic potential of pediatric oral medications: a literature. Int J Health Sci (Qassim). 201812: 75-82

33. Department of Health \& Social Care. Supply Disruption Alert: Slo-phyllin (Theophylline) $60 \mathrm{mg} / 125 \mathrm{mg} / 250 \mathrm{mg}$ capsules. www.cas.mhra.gov.uk/ViewandAcknowledgment/ViewAlert. aspx?AlertID=102936 Date last updated: November 28, 2019. Date last accessed: December 8, 2020.

34. Merck Serono Limited. Summary of product characteristics - Slo-Phyllin 60 mg capsules. www.medicines.org.uk/emc/ product/991/smpc Date last updated: April 11, 2018. Date last accessed: December 8, 2020.

35. Merck Serono Limited. Summary of product characteristics Slo-Phyllin 125 mg capsules. www.medicines.org.uk/emc/ product/7761/smpc Date last updated: April 11, 2018. Date last accessed: Dec 8, 2020.

36. Merck Serono Limited. Summary of product characteristics Slo-Phyllin 250 mg capsules. www.medicines.org.uk/emc/ product/7760/smpc Date last updated: April 11, 2018. Date last accessed: December 8, 2020.

37. Metaxa D, Hajnal A, Giggins C, et al. Prophylactic azithromycin dosing regimes in children at risk of lower respiratory tract infections: a literature review and survey in the east of England region. Arch Dis Child 2019; 104: A205.

38. Pfizer Limited. Summary of product characteristics - Zithromax Powder for Oral Suspension. www.medicines.org.uk/emc/ product/3006/smpc Date last updated: December 22, 2005. Date last accessed: March 8, 2021

39. Sandoz Limited. Summary of product characteristics Azithromycin 200 mg/5 mLPowder for Oral Suspension. www.medicines.org.uk/emc/product/441/smpc. Date last updated: August 8, 2020. Date last accessed: March 8, 2021.

40. Orenstein SR. Update on gastroesophageal reflux and respiratory disease in children. Can J Gastroenterol 2000; 14:, 131-135.

41. Department of Health \& Social Care. Supply Disruption Alert: Ranitidine: all formulations - second update. www. cas.mhra.gov.uk/ViewandAcknowledgment/ViewAlert. aspx?AlertID=102952 Date last updated: December 20, 2019. Date last accessed: March 72021.

42. Rosen R, Vandenplas $Y$, Singendonk $M$, et al. Pediatric gastroesophageal regflux clinical practice guidelines: joint recommendations of the North American Socieity for Pediatric Gastroenterology, Hepatology and Nutrition (NASPGHAN) and the European Society for Pediatric Gastroenterology, Hepatology and Nutrition (ESPGHAN). J Pediatr Gastroenterol Nutr 2018; 66: 516-554.

43. National Institute for Health and Care Excellence. Gastrooesophageal reflux disease in children and young people: diagnosis and management 2015. NICE guideline [NG1] www.nice.org.uk/guidance/ng1 Date last updated: October 9, 2019. Date last accessed: March 7, 2021.

44. British Thoracic Society, Scottish Intercollegiate Guidelines Network. British guideline on the management of asthma. A national clinical guideline. 2019. www.brit-thoracic.org. uk/document-library/guidelines/asthma/btssign-guidelinefor-the-management-of-asthma-2019/ Date last accessed: March 82021.
45. Dawson KP, Sharpe C. A comparison of the acceptability of prednisolone tablets and prednisolone sodium phosphate solution in childhood acute asthma. Aust J Hosp Pharm 1993; 23: $320-323$

46. Lucas-Bouwman ME, Roorda RJ, Jansman FGA, et al. Crushed prednisolone tablets or oral solution for acute asthma? Arch Dis Child 2001; 84: 347-348.

47. Medicines for Children. Prednisolone for asthma. www. medicinesforchildren.org.uk/prednisolone-asthma Date last updated: February 2018. Date last accessed: March 8, 2021.

48. Smyth J, ed. The NEWT Guidelines. 3rd Edn. Wrexham, Betsi Cadwaladr University Local Health Board (Eastern Division), 2015.

49. CF START. The cystic fibrosis (CF) anti-staphylococcal antibiotic prophylaxis trial (CF START); a randomised registry trial to assess the safety and efficacy of flucloxacillin as a longterm prophylaxis agent for infants with CF. www.cfstart.org.uk Date last accessed: November 22, 2020.

50. Batchelor H, Rayner O, Nickless J, et al. Children with cystic fibrosis: understanding issues related to oral administration of liquid flucloxacillin. Arch Dis Child 2016; 101: e2.

51. Rouse C, Mistry P, Rayner O, et al. A mixed methods study of the administration of flucloxacillin oral liquid; identifying strategies to overcome administration issues of medicines with poor palatability. Int J Pharm Pract 2017; 25: 326-334.

52. Mylan. Summary of product characteristics - Creon 10000 Capsules. www.medicines.org.uk/emc/product/1167/smpc Date last updated: January 23, 2017. Date last accessed: November 22, 2020.

53. Munck A, Duhamel JF, Lamireau T, et al. Pancreatic enzyme replacement therapy for young cystic fibrosis patients. J Cyst Fibros 2009; 8: 14-18.

54. Duerden M, Avery T, Payne R. The King's Fund: Polypharmacy and medicines optimisation: Making it safe and sound. www. kingsfund.org.uk/sites/default/files/field/field_publication_ file/polypharmacy-and-medicines-optimisation-kingsfundnov13.pdf Date last updated: 2013. Date last accessed: November 22, 2020.

55. Masnoon N, Shakib S, Kalisch-Ellett L, et al. What is polypharmacy? A systematic review of definitions. BMC Geriatr 2017; 17: 230.

56. Fraser-Pitt D, O’Neil D. Cystic fibrosis - a multiorgan protein misfolding disease. Future Sci OA 2015; 1: FSO57.

57. Harris RZ, Jang GR, Tsunoda S. Dietary effects on drug metabolism and transport. Clin Pharmacokinet 2003;42:1071-1088

58. Jordan CL, Noah TL, Henry MM. Therapeutic challenges posed by critical drug-drug interactions in cystic fibrosis. Paediatr Pulmonol 2016; 51: S44.

59. McDonnell AM, Dang $\mathrm{CH}$. Basic review of the cytochrome P450 System. J Adv Pract Oncol 2013; 4:263-268.

60. Nelson DR. The cytochrome P450 homepage. Hum Genomics 2009; 4: 59-65.

61. Shapiro LE, Shear NH. Drug interactions: proteins, pumps, and P-450 s. J Am Acad Dermatol 2002; 47:467-484.

62. Vertex Pharmaceuticals (Europe) Limited. Summary of product characteristics - Kaftrio 75 mg 50 mg 100 mg film-coated tablets. www.medicines.org.uk/emc/product/11724/smpc Date last updated: August 25, 2020. Date last accessed: November 22, 2020.

63. Vetex Pharmaceuticals (Europe) Limited. Summary of product characteristics - Orkambi $100 \mathrm{mg} / 125 \mathrm{mg}$ film coated tablets. www.medicines.org.uk/emc/product/8952/smpc Date last updated: September 17, 2020. Date last accessed: November 22, 2020.

64. Vertex Pharmaceuticals (Europe) Limited. Summary of product characteristics - Orkambi 100 mg/125 mg granules in sachet. www.medicines.org.uk/emc/product/9845/smpc Date last updated: September 17, 2020. Date last accessed: November 22, 2020.

65. Vertex Pharmaceuticals (Europe) Limited. Summary of product characteristics - Orkambi 150 mg/188 mg granules in sachet. www.medicines.org.uk/emc/product/10152/smpc Date last updated: September 17, 2020. Date last accessed: November 22, 2020 . 
66. Vertex Pharmaceuticals (Europe) Limited. Summary of product characteristics - Symkevi 100 mg/150 mg film coated tablets. www.medicines.org.uk/emc/product/9634/smpc Date last updated: August 25, 2020. Date last accessed: November 22 2020.

67. Vertex Pharmaceuticals (Europe) Limited. Summary of product characteristics - Kalydeco 150 mg Film-coated Tablets. www. medicines.org.uk/emc/product/3040/smpc Date last updated: November 23, 2020. Date last accessed: November 23, 2020

68. Vertex Pharmaceuticals (Europe) Limited. Kalydeco $25 \mathrm{mg}$ granules in sachet. www.medicines.org.uk/emc/ product/10982/smpc Date last updated: November 23 2020. Date last accessed: November 23, 2020.

69. Vertex Pharmaceuticals (Europe) Limited. Kalydeco $50 \mathrm{mg}$ granules in sachet. www.medicines.org.uk/emc/ product/1954/smpc Date last updated: November 23, 2020. Date last accessed: November 23, 2020.

70. Vertex Pharmaceuticals (Europe) Limited. Kalydeco $75 \mathrm{mg}$ granules in sachet. www.medicines.org.uk/emc/ product/10150/smpc Date last updated: November 23 2020. Date last accessed: November 23, 2020.

71. Medicines and Healthcare products Regulatory Agency. The Black Triangle Scheme: continued monitoring of medicines with a black triangle status. Drug Safety Update 2009. www. gov.uk/drug-safety-update/the-black-triangle-scheme-or Date last updated: December 11, 2014. Date last accessed November 22, 2020.

72. Medicines and Healthcare products Regulatory Agency. Yellow Card scheme. yellowcard.mhra.gov.uk/ Date last accessed November 22, 2020.

73. Medicines and Healthcare products Regulatory Agency. Yellow Card: Specific areas of interest for reporting suspected adverse drug reactions. assets.publishing.service.gov.uk/government/ uploads/system/uploads/attachment_data/file/403078/ Specific_areas_of_interest_for_adverse_drug_reaction_ reporting.pdf Date last accessed: November 22, 2020.

74. UK Medicines Information. Medicines Q\&As: What issues should be considered regarding drug induced QT prolongation? www.sps.nhs.uk/wp-content/uploads/2017/09/ QA237_2_DruginducedQTprolongation-2017-update.pdf
Date last updated: August 24, 2017. Date last accessed: November 22, 2020.

75. Baxter K, Preston CL, eds, Stockley's Drug Interactions. Drugs that prolong the QT interval+Other drugs that prolong the QT interval. www.medicinescomplete.com Date last updated: June 1, 2020. Date last accessed: November 22, 2020.

76. Kannankeril PJ, Roden DM. Drug-induced long QT and torsade de pointes: recent advances. Curr Opin Cardiol 2007; 22: 39-43.

77. CredibleMeds. Combined list of drugs that prolong QT and/ or cause Tosades de pointes (TDP). www.crediblemeds.org/ index.php/tools/pdfdownload?f=cql_en Date last updated: September 10, 2020. Date last accessed: November 22, 2020.

78. Pfizer Limited. Summary of product characteristics - VFEND $200 \mathrm{mg}$ film-coated tablets. www.medicines.org.uk/emc/ product/8408/smpc Date last updated: 2020 September. Date last accessed: November 27, 2020.

79. Kossoff EH, Zupec-Kania BA, Auvin S, et al. The Charlie Foundation, Matthew's Friends and the Practice Committee of the Child Neurology Society. Optimal clinical management of children receiving dietary therapies for epilepsy: Updated recommendations of the International Ketogenic Diet Study Group. Epilepsia Open 2018; 3:175-192.

80. Bergene EH, Tostein Baade R, Steinsbekk A. Strategies parents use to give children oral medicine: a qualitative study of online discussion forums. Scand J Prim Health Care 2017; 35: 221-228.

81. Organon Pharma (UK) Limited. Summary of product characteristics - Singulair Paediatric $4 \mathrm{mg}$ chewable tablets. www.medicines.org.uk/emc/product/6500/smpc Date last updated: August 25, 2007. Date last accessed: March 8, 2021.

82. Organon Pharma (UK) Limited. Summary of product characteristics - Singulair Paediatric 4 mg Granules. www. medicines.org.uk/emc/product/45/smpc Date last updated: August 25, 2007. Date last accessed: March 8, 2021.

83. Medicines and Healthcare products Regulatory Agency. Montelukast (Singulair): reminder of the risk of neuropsychiatric reactions. 2019. www.gov.uk/drug-safetyupdate/montelukast-singulair-reminder-of-the-risk-ofneuropsychiatric-reactions Date last accessed: March 8, 2021. 